\title{
Surgical Revascularization of Posterior Coronary Arteries without Cardiopulomonary Bypass
}

\author{
J. Glauco Lobo Filho, João Marcelo A. C. de Albuquerque, Carlos Bellini G. Gomes, \\ Rafael P. de Siqueira, Rodrigo M. Landim, Ricardo R. M. de Oliveira, Francisco M. de Oliveira, \\ Ciro Ciarline, J. Acácio Feitosa, Maria Claudia Leitão, Francisca Elita B. Pinheiro, \\ Erirtonio Façanha, J. Nogueira Paes Jr \\ Fortaleza, CE - Brazil
}

\begin{abstract}
Objective - To assess the results observed during the early postoperative period in patients who had the posterior coronary arteries revascularized without cardiopulmonary bypass $(C P B)$, in regard to the following parameters: age, sex, bypass grafts types, morbidity and mortality.

Methods - From January 1995 to June 1998, 673 patients underwent myocardial revascularization (MR). Of this total, 607 (90.20\%) MR procedures were performed without CPB. The posterior coronary arteries (PCA) were revascularized in 298 (44.27\%) patients, 280 (93.95\%) without CPB. The age of the patients ranged from 37 to 88 years (mean, 61 years). The male gender predominated, with 198 men (70.7\%). The revascularization of the posterior coronary arteries had the following distribution: diagonalis artery (31 patients, 10\%); marginal branches of the circumflex artery (243 patients, 78.7\%); posterior ventricular artery (4 patients, $1.3 \%)$; and posterior descending artery (31 patients, 10\%).
\end{abstract}

Results - Procedure-related complications without death occurred in 7 cases, giving a morbidity of $2.5 \%$. There were 11 deaths in the early postoperative period (mortality of $3.9 \%$ ).

Conclusion - Similarly to the anterior coronary arteries, the posterior coronary arteries may benefit from myocardial revascularization without $C P B$.

Key words: myocardial revascularization, cardiopulmonary bypass, minimally invasive surgery

Instituto do Coração e Pulmão ICORP, Hospital Prontocárdio and Hospital Antônio Prudente - Fortaleza.

Mailing address: J. Glauco Lobo F ${ }^{\circ}$ Rua Dr. José Lourenço, 625 - 60115-280 Fortaleza, Ceará - Brazil
Since the original reports by Ankeney ${ }^{1}$, Benetti et al ${ }^{2,3}$ and Buffolo et $\mathrm{al}^{4}$, the use of myocardial revascularization (MR) without cardiopulmonary bypass (CPB) has increased. Median sternotomy is the preferred approach, but other authors are performing the revascularization of the anterior descending coronary artery through a small incision in the anterolateral region of the left hemithorax ${ }^{5,6}$. These authors use the left internal thoracic artery (LITA) as the conduit of choice.

In view of the difficulty in performing the revascularization of the posterior coronary arteries (PCA), there is a constant search for techniques to improve the surgical approach to these arteries. Beginning in January 1995, we developed a technique in the UNITORAX-PE clinic located in the Northeastern region of Brazil, allowing us to perform the revascularization of most PCAs. We consider PCAs the following arteries: diagonalis artery (DIA), marginal branches of the circumflex artery (MCX), posterior ventricular artery (PVA), and posterior descending artery (PDA).

\section{Methods}

Between January 1995 and June 1998, 673 patients underwent MR in our clinic. Of these 673 surgeries, 607 (90.2\%) were performed without CPB. Of the total number of MR surgeries, $298(44.27 \%)$ involved grafts for one or more PCAs and 280 (93.95\%) of these procedures were performed without CPB (tab. I). Considering this specific group of patients who received PCA grafting without $\mathrm{CPB}$, a total of 309 grafts for PCA were performed. Age ranged from 37 to 88 years (mean, 61 years). There was a preponderance of the male gender, with $198(70.7 \%)$ men. The surgical approach was always made through median sternotomy. Three catgut \# 0 threads were inserted in the posteroinferior area of the pericardium, to the left, between the left inferior pulmonary 


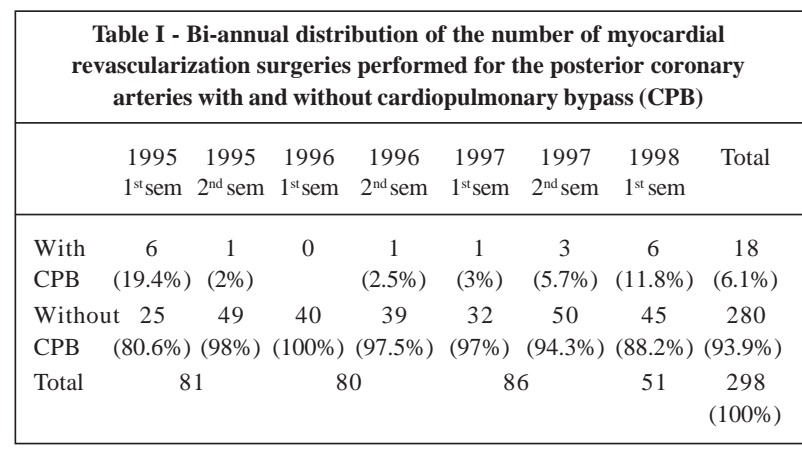

vein and the inferior vena cava. The traction of these threads caused the mediastinum to rotate to the left, displacing the heart to the right. This procedure does not usually result in hemodynamic abnormalities, thus providing an excellent approach for PCAs (fig. 1).

Heparin sodium, $2 \mathrm{mg} / \mathrm{kg}$ of body weight, was used for anticoagulation. This anticoagulation was maintained, with the hourly administration of half of the initial dose of heparin. Interruption of the blood flow to the coronary areas, where the anastomoses must be performed, was achieved using a 4-0 or 5-0 polypropylene thread in a figure-eight shape with delicate tourniquets placed in the areas located

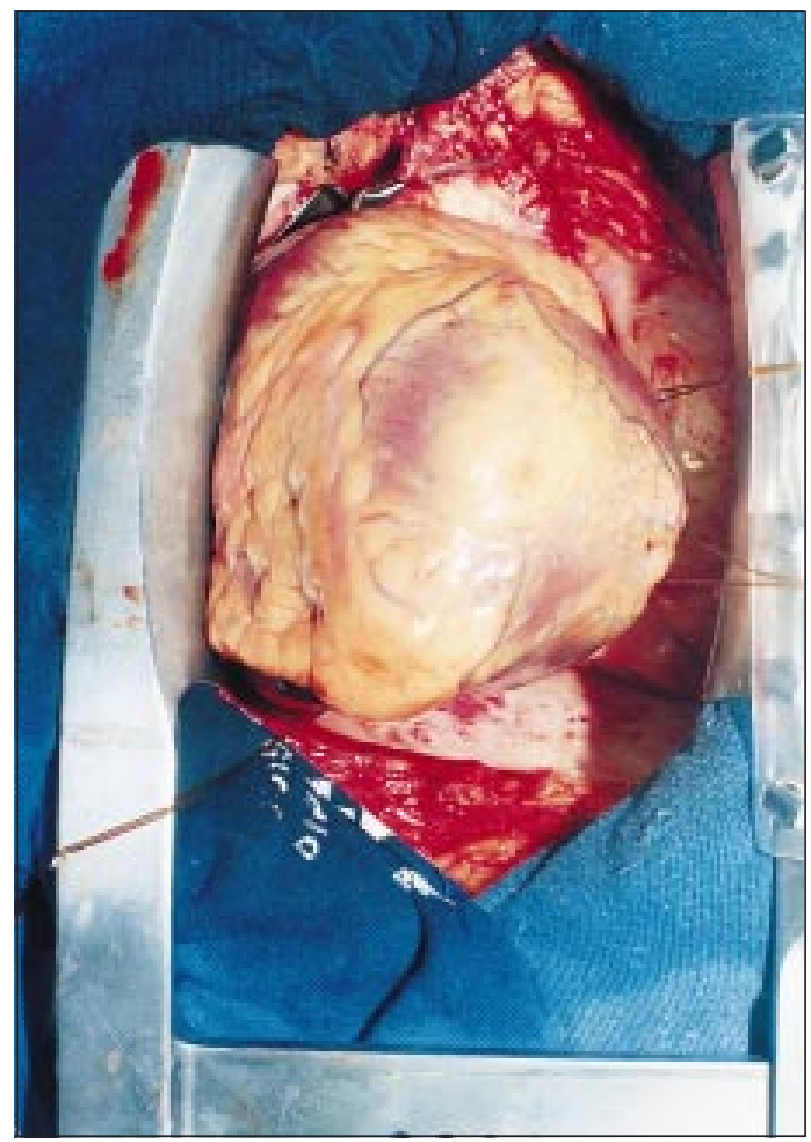

Fig. 1 - Exposure of the posterior coronary arteries after right mediastinal rotation through traction of the threads inserted to the left of the posteroinferior area of the pericardium.

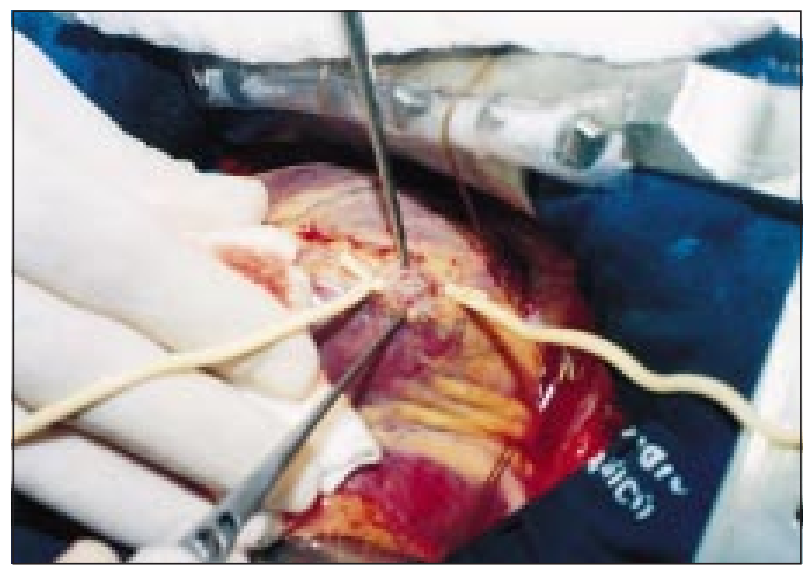

Fig. 2-Protection of the coronary arterial bed with a small $(1.0 \mathrm{~cm})$ segment of Folley catheter \# 8 during coronary clamping.

proximal and distal to the site of the anastomosis. In order to protect the coronary artery bed, a small segment $(1.0 \mathrm{~cm})$ of Folley catheter \#8 is interposed between the tourniquets and the coronary artery (fig. 2). The anastomosis was performed using a single 7-0 or 8-0 polypropylene thread.

The use of beta-blockers during the preoperative period was contraindicated, whenever possible. Patients who receiveed beta-adrenergic blockade tended to develop episodes of refractory hypotension when the heart was manipulated during the anastomoses.

The revascularized posterior arteries had the following distribution: 243 for MCX (78.7\%), 31 for DIA (10\%), 31 for PDA (10\%) and 4 for PVA (1.3\%).

The most frequently used bypass graft was the vena saphena magna, employed in $302(97.7 \%)$ anastomoses; the radial artery was used in 4 cases $(1.3 \%)$, but the LITA was used in only 3 cases $(1.0 \%)$.

Statistical analysis of the frequency of stenosis in the anastomoses of randomly assessed patients was performed using the rank sum test ${ }^{7}$.

\section{Results}

In our clinic, morbidity is represented by patients with the following complications in the early postoperative period (POP): acute myocardial infarction (AMI), stroke, cardiac tamponade, bleeding requiring reoperation, sternal dehiscence, mediastinitis, acute renal failure and infection of the wall. We had 7 nonfatal complications in the early POP in our series (tab. II), giving a total morbidity of $2.5 \%$. Also,

\begin{tabular}{|lcc|}
\hline \multicolumn{2}{|c|}{ Table II - Major complications during the early postoperative period } \\
\hline Complications & \#of cases & Percentage \\
\hline Sternal Dehiscence & 1 & 0.36 \\
Bleending & 1 & 0.36 \\
Acute renal failure & 1 & 0.36 \\
Stroke & 2 & 0.71 \\
Acute myocadial infarction & 2 & 0.71 \\
Total & 7 & $2.5 \%$ \\
\hline
\end{tabular}




\begin{tabular}{|lcc|}
\hline \multicolumn{2}{|c|}{ Table III - Causes of death in the early postoperative period } \\
\hline Causes & \# of cases & Percentage \\
\hline Acute myocardial infarction & 2 & 0.72 \\
Stroke & 1 & 0.36 \\
Ventricular fibrillation & 1 & 0.36 \\
Bleeding & 1 & 0.36 \\
Cardiac arrest & 1 & 0.36 \\
Cardiogenic Shock & 1 & 0.36 \\
Arrhythmias & 1 & 0.36 \\
Pulmonary embolism & 1 & 0.36 \\
Sudden death & 1 & 0.36 \\
Unknown & 1 & 0.36 \\
Total & 11 & $3.9 \%$ \\
\hline
\end{tabular}

in this period, we had a $3.9 \%$ mortality, with 11 deaths. The causes of these deaths are shown in table III.

In relation to permeability of anastomoses, which is a controversial aspect for those who are not familiar with this technique, we believe that the very low incidence of AMI in the early POP, the marked clinical improvement shown by the patients, the minimally traumatic nature of the anastomoses and the results of the tests conducted at the end of these procedures make these grafts largely safe, when permeability is taken into account.

As we were still not satisfied with this evidence, from January to June 1998, we conducted, random angiographic studies in 34 out of the 45 patients $(75 \%)$ who underwent MR without $\mathrm{CPB}$ and received PCA grafting. This study showed no evidence of stenosis in $100 \%$ of the anastomoses (fig. 3). This result was highly statistically significant according to the rank sum test, with $p=(1 / 2)^{34}=6 \times 10^{-11}$. Thus, the efficacy of this procedure could be demonstrated. The patients were studied during a period that ranged from 5 to 120 days (mean, 32 days).

\section{Discussion}

Currently, increasingly critical patients are being referred for the MR procedure. This has stimulated heart sur-

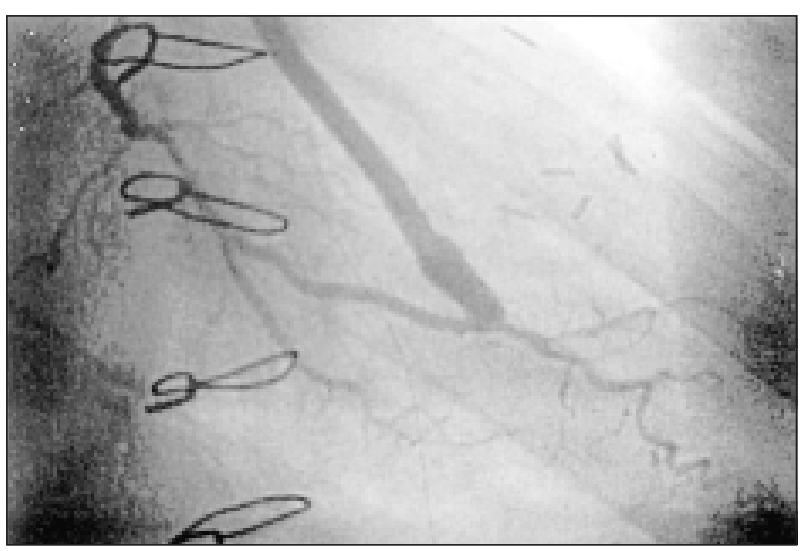

Fig. 3-Hemodynamic study of a large saphenous vein graft implanted in a marginal branch of the circumflex artery. geons worldwide to search for less invasive and more effective techniques ${ }^{8}$ At the same time, more cost-effective procedures are being developed, without compromising the quality of the results.

Within the global scenario of heart surgery, we consider that minimally invasive surgery should be, above all, a procedure that does not use $\mathrm{CPB}$, as $\mathrm{CPB}$ is considered the most important factor in the genesis of most surgical complications, especially in those individuals regarded as high-risk patients ${ }^{9,11}$. In addition to all the systemic damage caused by $\mathrm{CPB}$, it is worth noting that $\mathrm{CPB}$ imposes additional costs on the procedures, as a result of the elevated costs of its circuits, of the use of blood derivatives and of the prolonged hospital stay in the POP ${ }^{12-14}$.

In the last 3 years, our group has refined some techniques that allow us, at the moment, to perform $95 \%$ of the MR procedures, including revascularization of PCA, without the use of CPB, as reported here. In the remaining 5\%, CPB was employed as a circulatory support, because the anastomoses were performed with a beating heart, that is, without aortic clamping. This amount of procedures without CPB is much higher than the average figures shown in other studies ${ }^{12,15}$.

Several reports have shown that the MR procedure without CPB may bring benefit to the anterior arteries of the heart ${ }^{14,15}$. The latest literature on this topic, particularly the publications from national and international referral centers, does not mention the systematic use of PCA grafting without $\mathrm{CPB}{ }^{15}$, in spite of the increased number of patients who had these arteries bypassed and benefited from this technique. In those studies, PCA grafting is seldom employed. Overall, according to our experience with the use of the technique described above, only patients with cardiomegaly and low ejection fraction cannot receive PCA grafting without CPB.

In this series, we did not use retractors with the socalled stabilizers, or intracoronary perfusion device. However, we believe that the increased use of this technology, mainly in relation to stabilizers, would undoubtedly ease and simplify this procedure, so that it could be performed by a larger number of teams and benefit a larger number of patients.

In view of the data presented and discussed in this report, we believe that, currently, the use of MR surgery without CPB, including patients who need PCA grafting, is not a futurist prediction, but, instead, a realistic scenario. The simplicity of this technique, coupled with the good results achieved and the lower costs, make this procedure an increasingly frequent option in the treatment of coronary heart disease, both in its acute and chronic phases.

Finally, we would like to note that "The limits of human capacity and knowledge are unpredictable. The objective of technology and science is to allow the development of these qualities". 


\section{References}

1. Ankeney JL. To use or not to use the pump oxygenator in coronary bypass operations. Ann Thorac Surg 1975; 19: 109.

2. Benetti FJ. Cirurgía coronaria directa con bypass de vena safena sin circulación extracorpórea oparada cardíaca. Comunicación previa. RevFArg Cardiol 1980;8:3.

3. Benetti FJ. Direct coronary artery surgery with saphenous vein bypass without either cardiopulmonary bypass or cardiac arrest. J Cardiovasc Surg 1985; 26: 217-22.

4. Buffolo E, Andrade JCS, Succi JB, et al. Revascularização do miocárdio sem circulação extracorpórea: descrição da técnica e resultados iniciais. Arq Bras Cardiol 1983; 41:309-16.

5. Calafiore AM, Di Giammarco G, Teodori G, et al. Left anterior descending coronary artery grafting via left anterior small thoracotomy without cardiopulmonary bypass. Ann Thorac Surg 1996; 61: 1658-65.

6. Lobo Filho JG, Oliveira FM, Ciarlini C, et al. Cirurgia de revascularização do miocárdio através de minitoracotomia ântero-lateral esquerda . Rev Bras Cir Cardiovascular 1996; 11: 143-7.

7. Bradley, James V. Distribution Free Statistical Tests. New Jersey: Prentice-Hall, Inc, 1968.
8. Pfister AJ, Garcia JM, Corso PJ, et al. Coronary artery bypass without cardiopulmonary bypass. Ann Thorac Surg 1992; 54: 1085-92.

9. Kirklin JK, Westaby S, BlackstoneEH, et al. Complement and damaging effects of cardiopulmonary bypass. J Thorac Cardiovasc Surg 1983; 86: 845-57.

10. Blauth CI, Arnold JV, Schulenberg WE, et al. Cerebral microembolism during cardiopulmonary bypass. J Thorac Cardiovasc Surg 1988; 95: 668-76.

11. Butler J, Rocker GM, Westby S, et al. Inflammatory response to cardiopulmonary bypass. Ann Thorac Surg 1993; 55: 553-59.

12. Buffolo E, Gomes WJ, Andrade JC, et al. Revascularização do miocárdio sem circulação extracorpórea. Resultados cirúrgicos em 1090 pacientes. Arq Bras Cardiol 1994; 62: 149-53.

13. Accuf TE, Landreneau RJ, Griffith BP, et al. Minimally invasive coronary artery bypass grafting. Ann Thorac Surg 1996; 61: 135-7.

14. Telles CA, Aguiar LF, Pelrizzo A, et al. Revascularização do miocárdio através de minitoracotomia. Arq Bras Cardiol 1997; 68: 112-16.

15. Westbay S. Coronary surgery without cardiopulmonary bypass. Br Heart J 1995; 73: 203-5. 